\title{
Analysis of the Dynamic Stability of Ball-End Milling of AISI D6 Hardened Steel
}

\author{
Milton Luiz Polli ${ }^{a} \mathbb{C}$, Fábio Fernandes da Silva ${ }^{b}$ \\ ${ }^{a}$ Universidade Tecnológica Federal do Paraná (UTFPR), Av. Sete de Setembro, 3165, Rebouças, \\ CEP 80230-901, Curitiba, PR, Brasil \\ ${ }^{b}$ Instituto Federal de Educação Ciência e Tecnologia do Paraná (IFPR), Av. Cívica, 475, Centro Cívico, \\ CEP 85935-000, Assis Chateaubriand, PR, Brasil
}

Received: December 11, 2018; Revised: July 16, 2019; Accepted: September 29, 2019

\begin{abstract}
AISI D6 hardened steel is a difficult to cut material that it is employed in mould and die manufacturing where long ball-end mills are frequently required to machine deep cavities. This condition can lead to excessive vibration between tool and workpiece resulting in a poor surface finishing and reduced tool life. This work analyses the dynamic stability of ball-end milling of AISI D6 hardened steel for different tool path orientations at inclined workpiece angles of $15^{\circ}$ and $75^{\circ}$. The evaluation of stability is based on the surface texture and spectrum analysis of the vibration signals. The results showed that for workpiece inclination angle of $15^{\circ}$ chatter occurred in vertical upward down-milling and vertical downward up-milling. Best surface texture with tool marks consistent with pick feed and feed directions were generated by applying horizontal downward tool paths that produced the least vibration. Only forced vibrations occurred for the workpiece inclination angle of $75^{\circ}$. The highest peaks of the spectra corresponded to the harmonics of the tooth passing frequency closer to the natural frequency of the system. High magnitudes in the spectrum were found for vertical upward down-milling that generated a less uniform surface texture.
\end{abstract}

Keywords: ball-end miling, tool path, surface texture, vibrations.

\section{Introduction}

AISI D6 is a cold work tool steel with excellent resistance to wear and abrasion. Its high structural and mechanical features make this material important in mould and die manufacturing. However, machine form tools with this material is a difficult task. ${ }^{1-2}$ Long ball-end mills with high length to diameter ratios are frequently required to machine deep cavities of moulds and dies. The low stiffness of the system can lead to excessive vibration between tool and workpiece for certain operation conditions resulting in a poor surface finishing and reduced tool life.

The relative vibrations between tool and workpiece highly influence the result of the process. Free vibrations, forced vibrations and self-excited vibrations may be present during machining operations. Self-excited vibrations, also called chatter, result from a self-excitation mechanism in the generation of chip thickness during machining operations. They may be caused by mode coupling or regeneration of the chip thickness. The mode coupling chatter occurs when there are vibrations in two directions in the plane of cut. The regenerative chatter results from phase differences between the vibration waves left on both sides of the chip and occurs earlier than the mode coupling in most machining cases. ${ }^{3}$ This type of vibration leads the system to instability.
Over the years, many researchers investigated chatter vibration in the milling process. Tlusty and Ismail ${ }^{4}$ have developed time-domain, numerical simulations of the milling operation that allows details of the cutting process to be examined. Altintas and $\mathrm{Budak}^{5}$ presented an analytical model for prediction of milling stability by using a Fourier seriesbased method for handling the time-dependent directional dynamic milling force coefficients and achieved reasonably accurate results. Altintas and $\mathrm{Lee}^{6}$ extended the analytical model to predict the stability limits in ball-end milling but the tool inclination has not been considered. Shamoto and Akazawa $^{7}$ developed a method to compute the directional milling force coefficients considering the tool inclination and applied it to predict chatter stability in ball-end milling. These models have some limitations in finishing operations when low radial immersions are employed and the time the tool spend cutting is just a small fraction of one rotation period. Denkena et al. ${ }^{8}$ presented a combined approach using the kinematic topography from the machining simulation and added a stochastic topography based on empirical data. It could be shown, that the usage of the stochastic topography greatly affects the flow losses and thus cannot be ignored in ball-end milling.

The contact between tool and machine surface changes constantly in free form milling, particularly in finishing operations. 
The cutting force has significant influence on part accuracy and tool life in complex machining by ball-end milling. ${ }^{9}$ Previous works investigated the influence of tool path orientation on the ball-end milling of inclined surfaces for different materials. Elbestawi et al. ${ }^{10}$ reported that a significant increase in tool life when upward tool path orientation at an inclination of $10^{\circ}$ was employed in milling of AISI H13 tool steel. Schultz and Hock ${ }^{11}$ pointed out that a vertical upward orientation at an inclination angle of $15^{\circ}$ results in the best tool life because the machining forces and the cutter vibrations were minimum in milling of $40 \mathrm{CrMnMo} 7$ steel. Toh ${ }^{12}$ evaluated different tool path orientation when high-speed milling AISI H13 hardened steel at a workpiece inclination angle of $75^{\circ}$. He found that employing a vertical downward orientation achieved the longest life. However, in terms of workpiece surface texture, vertical upward orientation is generally preferred. The cutter paths generated by up-milling were noticeably higher than the cutter path formed by down-milling orientations. The increase in workpiece surface roughness when employing a horizontal downward orientation was due to side flow ${ }^{13}$. Tan et al. ${ }^{14}$ studied the influence of cutter path orientation at an incline workpiece angle of $30^{\circ}$ on finish milling of titanium alloy TC17. They concluded that in the aspect of tool wear reduction and improvement of surface integrity, horizontal upward cutter path orientation was a suitable choice. Souza et al. ${ }^{15}$ investigated the tool-workpiece interactions in free-form milling of AISI P20 using a ball-end mill. They concluded that when the tool tip center is in the cut region, the material is removed by shearing together with plastic deformation. Such conditions increase the cutting force and surface roughness and lead to an unstable machining process.
The ascendant cutting showed to be the best option, because the effective tool diameter is larger and ploughing occurs in a minor zone of the cut. On the other hand, Scandiffio et al. ${ }^{16}$ evaluated the surface roughness, tool life and machining force when milling free-form shapes on hardened AISI D6 steel. They reported that descendent milling favored lower workpiece surface roughness and higher tool life. They pointed out that the engagement of the tool during cutting is advantageous for the machining process of hard materials because it improves cutting stability and decreases vibrations. Although these previous experimental works reported the occurrence of vibration during the process, the authors did not perform a spectrum analysis taking in consider the natural frequency of the system, the tooth-passing frequency and the vibration frequencies.

The present work analyses the dynamic stability of ballend milling of AISI D6 hardened steel for different tool path orientations at inclined workpiece angles of $15^{\circ}$ and $75^{\circ}$. The evaluation of stability is based on the surface texture and spectrum analysis of the vibration signals.

\section{Experimental Procedure}

Tests were carried out in a machining center Romi D600 with a maximum spindle speed of $10,000 \mathrm{rpm}$ and $16.5 \mathrm{~kW}$ power. A $12 \mathrm{~mm}$ diameter indexable ball-end mill with carbide inserts coated with (Ti,Al)N and two flutes was used in the experiments. The tool overhang was $96 \mathrm{~mm}$. The workpiece material was AISI D6 steel with $58 \mathrm{HRc}$ with dimensions of $40 \times 40 \times 25 \mathrm{~mm}$.

Finishing ball-end milling were performed with eight different tool path orientations at inclined surfaces of $15^{\circ}$ and $75^{\circ}$. The nomenclature adopted is described in Table 1 and details of the tool path orientations are shown in Figure 1.

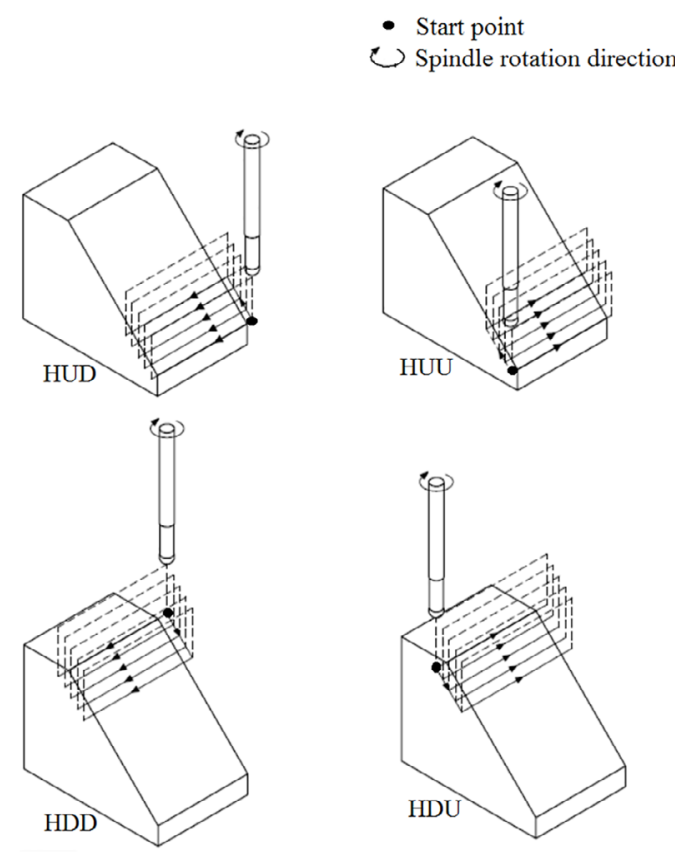

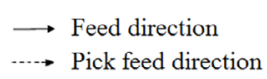
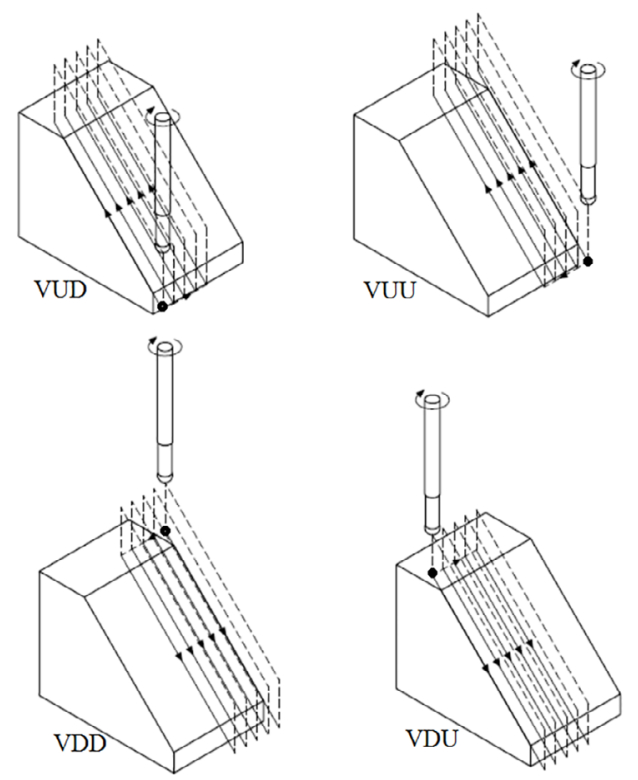

Figure 1. Tool path orientations 
Table 1. Description of tool path orientations employed

\begin{tabular}{lc}
\hline & Tool path orientation \\
\hline HUD & Horizontal Upward Down-milling \\
HUU & Horizontal Upward Up-milling \\
HDD & Horizontal Downward Down-milling \\
HDU & Horizontal Downward Up-milling \\
VUD & Vertical Upward Down-milling \\
VUU & Vertical Upward Up-milling \\
VDD & Vertical Downward Down-milling \\
VDU & Vertical Downward Up-milling \\
\hline
\end{tabular}

Axial and radial depths of cut of $0.2 \mathrm{~mm}$, feed per tooth $\left(f_{\mathrm{z}}\right)$ of $0.1 \mathrm{~mm}$ and spindle speed of $6600 \mathrm{rpm}$ were the cutting parameters selected for the tests. The resulting tooth-passing frequency was $220 \mathrm{~Hz}$.

Tool-tip Frequency Response Function (FRF) was obtained by attaching an accelerometer to the end of the tool, striking the tool in the direction of the accelerometer with an instrumented hammer and recording the signals simultaneously by using a signal analyzer. The measured natural frequency of the system was $795 \mathrm{~Hz}$. In order to measure the vibration signals during the process an accelerometer was attached to the spindle housing of the machine center. A spectrum analysis of the vibration signals was further performed. Measurements of the acceleration signal were made during pre-tests and indicated that frequencies that could be related to noise did not present significant magnitude in the frequency spectrum. Thus, it was not necessary to conduct filtering to remove noise not related to the machining process.

(a)

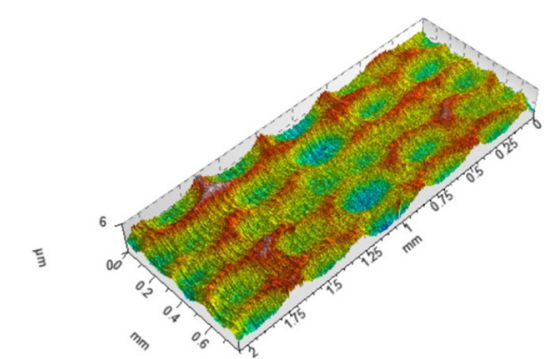

(c)
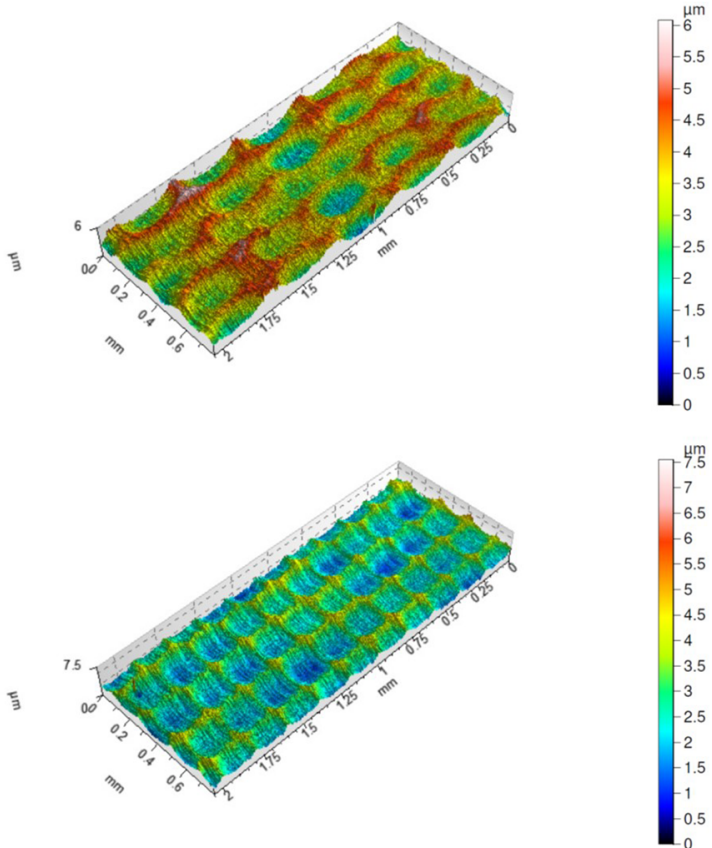

Surface texture of the machined surfaces were evaluated by using an optical profiler Talysurf CCI from Taylor Hobson Precision.

\section{Results and Discussions}

Figure 2 shows the surface topographies generated by vertical tool path orientations at inclined workpiece angle of $15^{\circ}$. Relative isotropic surfaces resulted from vertical downward down-milling and vertical upward up-milling. The direction of the tool marks is consistent with the step and feed direction. The machined surface is composed of U shape marks in both directions forming a cross-linked pattern. These tool path orientations produced stable cuts. On the other hand, machined surfaces generated using vertical upward down-milling and vertical downward upmilling are not uniform and the tool marks are inconsistent in size with the cutting parameters. The machined surface was significantly deteriorate due to dynamic instability during the process.

Figure 3 depicts the frequency spectra of the measured acceleration signals for the vertical tool path orientations at inclined workpiece angle of $15^{\circ}$. For the stable cuts (VDD and VUU) the spectra consist of the harmonics of the spindle speed $\left(f_{t} / 2\right)$ and the tooth passing frequency $\left(f_{t}\right)$. However, for the unstable conditions (VUD and VDU) there are considerably high peaks at frequencies that are not harmonics of the tooth passing frequency. There is a high peak at $833 \mathrm{~Hz}\left(\mathrm{f}_{\mathrm{cl}}\right)$ in the spectrum of the VDU that is close to the natural frequency of the system $(795 \mathrm{~Hz})$ and another one at $1053 \mathrm{~Hz}\left(\mathrm{f}_{\mathrm{c} 2}\right)$.

(b)

(d)
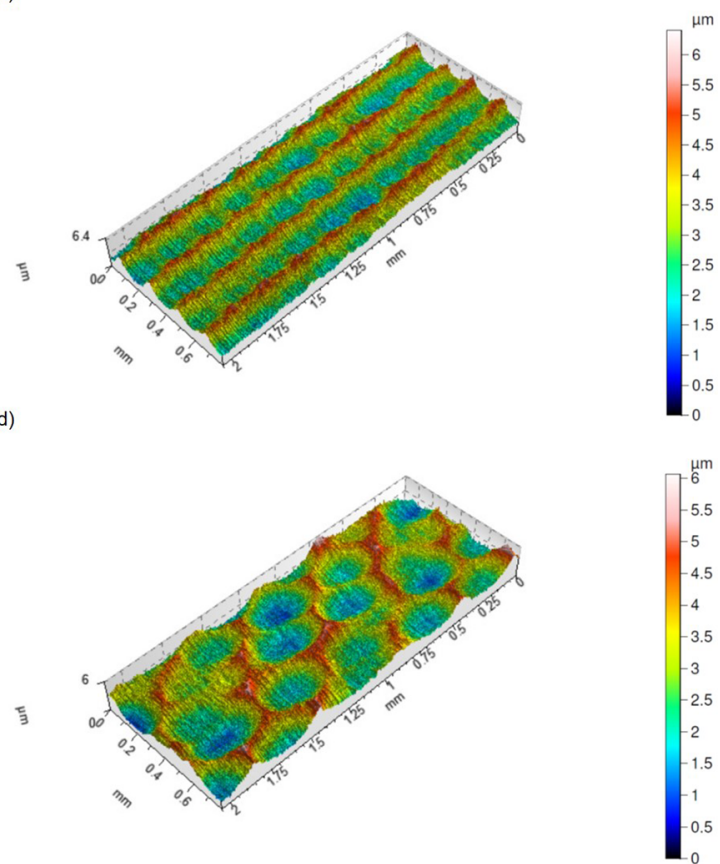

Figure 2. Surface topographies generated by vertical tool path orientations at inclined workpiece angle of $15^{\circ}$ (a) VUD, (b) VUU, (c) VDD, (d) VDU 
The highest peak of the spectrum for VUD occurs at $880 \mathrm{~Hz}$ (4f) that corresponds to the harmonic of the tooth-passing frequency closer to the natural of the system. Nevertheless, high peaks at $828 \mathrm{~Hz}\left(\mathrm{f}_{\mathrm{cl}}\right)$ and $1048 \mathrm{~Hz}\left(\mathrm{f}_{\mathrm{c} 2}\right)$ are also present. Therefore, chatter vibrations occurred during milling with both tool path orientations.

(a)

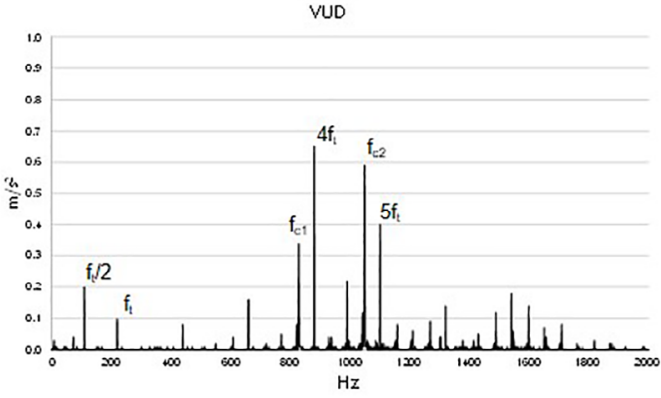

(c)

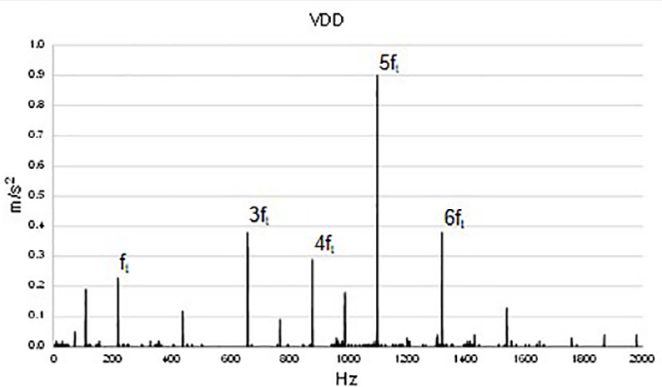

Figure 4 illustrates the surface profile measured along the feed direction when VDD and VUD were employed. In finishing milling with ball-end mills the surface is generated in a small amount of time during the tool engagement. This situation occurs when the tool is at the entry in up-milling or at the exit in down-milling ${ }^{3}$.

(b)

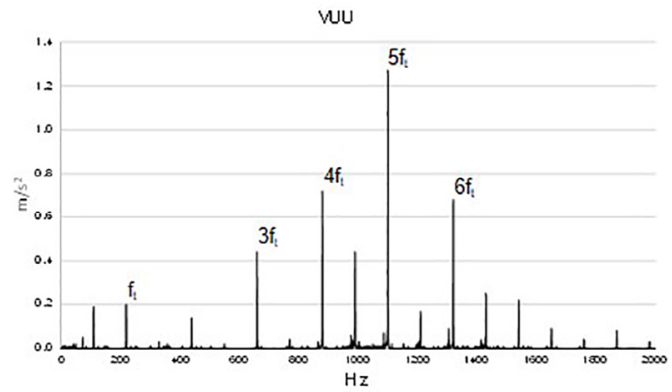

(d)

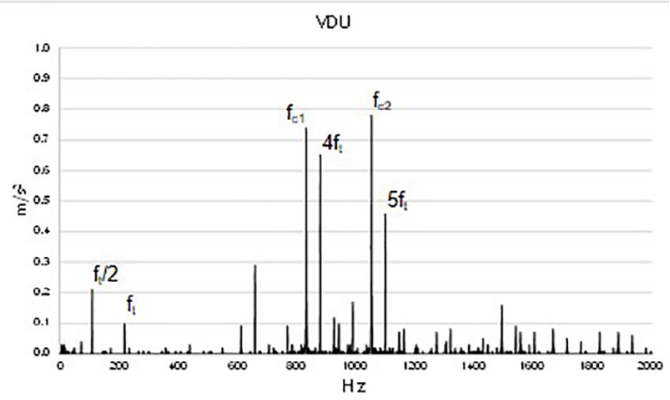

Figure 3. Spectrum of the acceleration signals for vertical tool path orientations at inclined workpiece angle of $15^{\circ}$ (a) VUD, (b) VUU, (c) VDD, (d) VDU

(a)

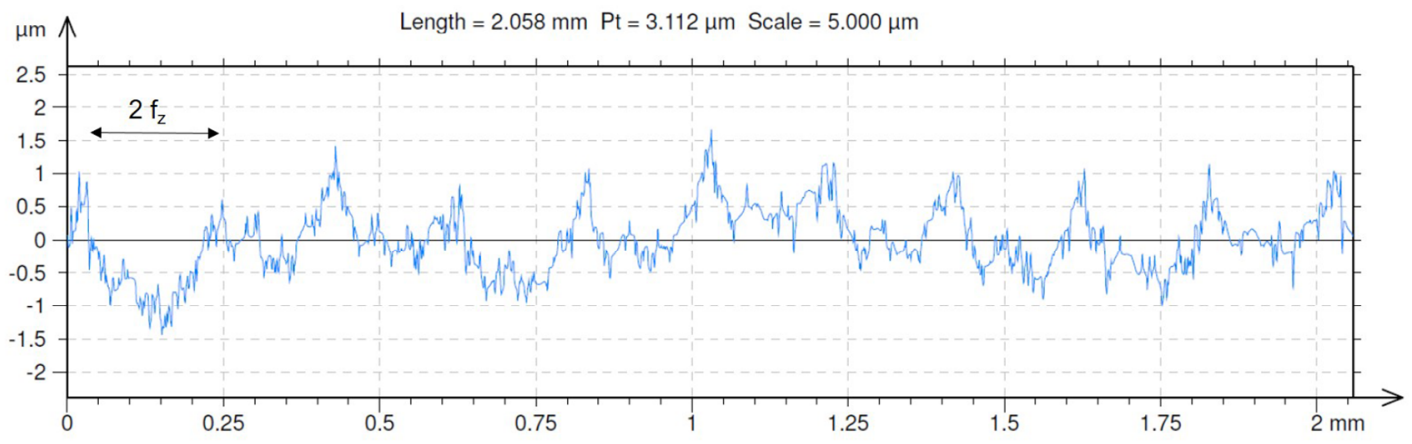

(b)

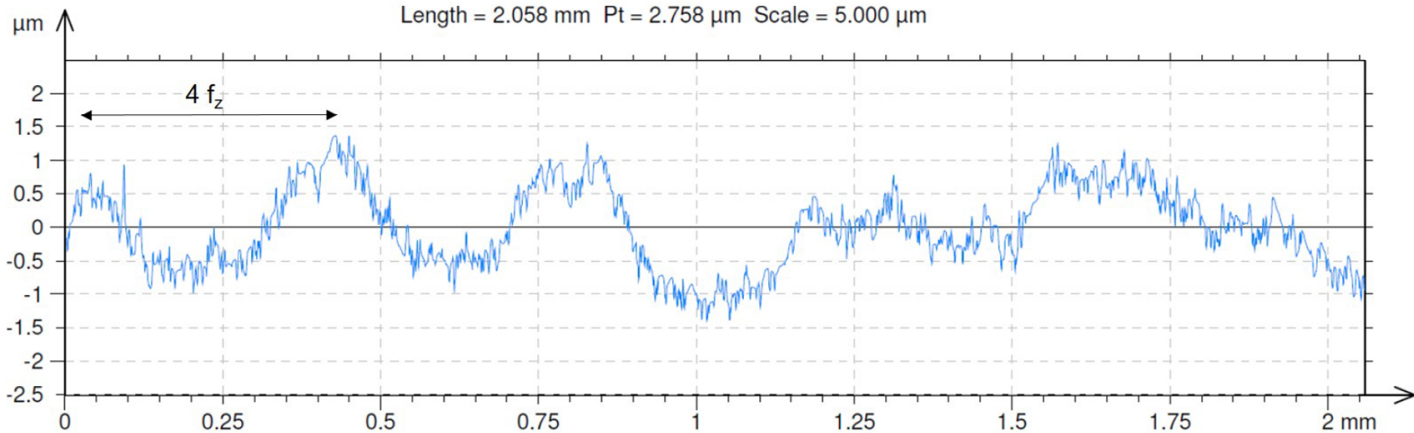

Figure 4. Surface profile along the feed direction (a) VDD, (b) VUD 
Tool vibrations are imprinted on the surface only at this moment and they change the position of the feed marks in the surface profile. The amplitude, frequency and phase of the vibrations have direct influence on surface topography. When the tool vibrates with the tooth passing frequency and its harmonics, the amplitude is almost the same at every toothpassing period and the vertical position of the feed marks in the surface profile is less affected. That was the case of vertical downward down-milling. The distance between the marks observed in the profile of VDD corresponds mainly to the feed per revolution due to tool run-out and forced vibrations (Fig. 4a). Although both flutes take part in the process, the eccentric flute removes partially the marks left by the other one.

On the other hand when the tool vibrates with a frequency different from the tooth passing frequency and its harmonics, the vibration amplitude is totally different at every tooth passing period altering significantly the positioning of the feed marks in the peak to valley surface profile. The marks of lower depth generated by one flute can be removed by the other one or even by the same flute during the next revolution depending on the vibration amplitude. That was the case of vertical upward down-milling. The profile of VUD is more wavy and the distance between the marks reaches the double of the feed per revolution (Fig. 4b).

According to Lim et al. ${ }^{17}$ and Toh $^{12}$ the higher forces observed when employing a vertical downward orientation tend to deflect the cutter towards the machined surface. On the other hand a vertical upward would tend to deflect away from the machined surface. As a long tool overhang was employed in the experiments the tool deflects toward the surface in up-milling causing an overcut or deflects away from the surface in down-milling causing an undercut. Thus, for VUD there is a high tendency of the tool to deflect toward the surface, while for VDU there is a there is a high tendency of the tool to deflect away the surface. The sum of these effects can be the reason why VUD and VDU resulted in unstable cuts.

Figure 5 presents the surface topographies generated by horizontal tool path orientations at inclined workpiece angle of $15^{\circ}$. These conditions resulted in stable cuts. The best surface topography were found for HDD and HDU that exhibit more uniform $U$ shape marks consistent in size with the cutting parameters .

Figure 6 shows the frequency spectra of the measured acceleration signals for the horizontal tool path orientations at inclined workpiece angle of $15^{\circ}$. No chatter occurred for these conditions. The spectra consist of the harmonics of the spindle speed and the tooth passing frequency $\left(f_{t}\right)$. For HDD and HDU the highest peaks correspond to the tooth passing frequency. Meanwhile, for HUD and HUU the vibration amplitudes were higher and the highest peaks of the spectrum corresponds to the harmonics of the tooth-passing frequency closer to the natural frequency of the system.

In ball-end milling the effective tool diameter alters along the toolpath depending on the surface inclination. The cutting speed at the contact point for the workpiece angle of $15^{\circ}$ is lower than the one for $75^{\circ}$. This fact has influence on the components of the machining force and surface roughness. According to Souza et al. ${ }^{15}$ reducing the effective cutting diameter reduces the cutting speed, thus increasing the machining forces. Moreover, plastic deformation can occur at low cutting speed resulting in higher surface roughness. (a)

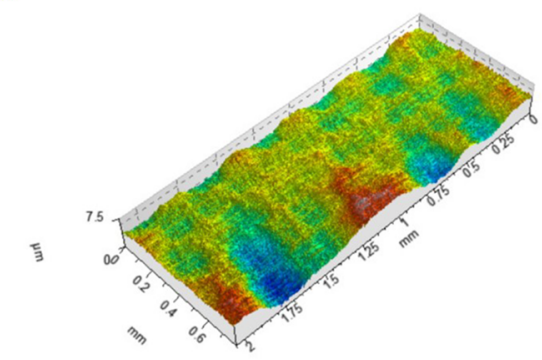

(c)

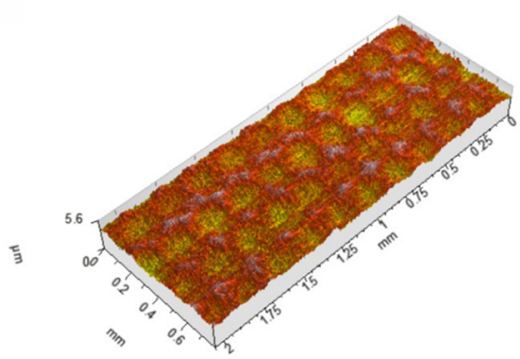

(b)

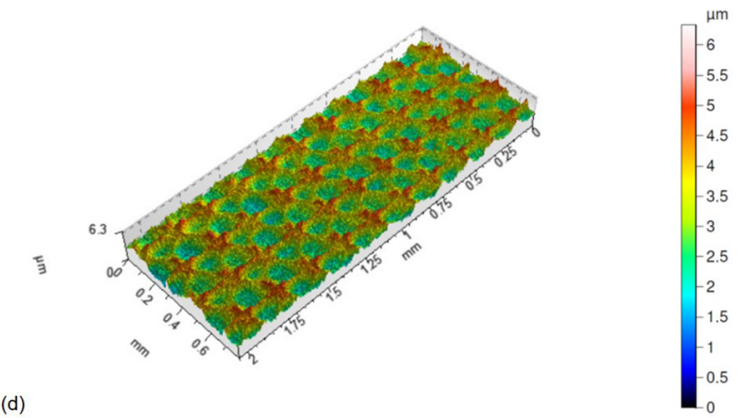

(d)

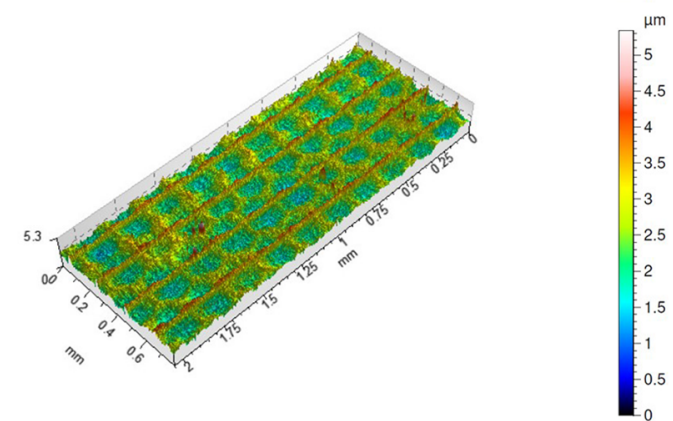

Figure 5. Surface topographies generated by horizontal tool path orientations at inclined workpiece angle of $15^{\circ}$ (a) HUD, (b) HUU, (c) HDD, (d) HDU 
Figure 7 presents the surface topographies generated by vertical tool path orientations at inclined workpiece angle of $75^{\circ}$. No chatter marks can be observed for these conditions. VDU generated a more uniform surface in feed and cross feed directions. It is possible to notice tool marks corresponding to $3 / 2 \mathrm{f}_{\mathrm{z}}$ and $1 / 2 \mathrm{f}_{\mathrm{z}}$ with almost the same depth along the feed direction. In this case, both flutes generates the surface and the eccentric flute removes partially the marks left by the other one.

(a)

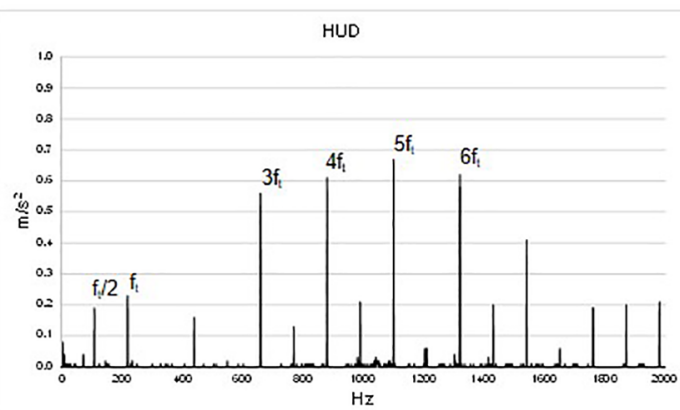

(c)

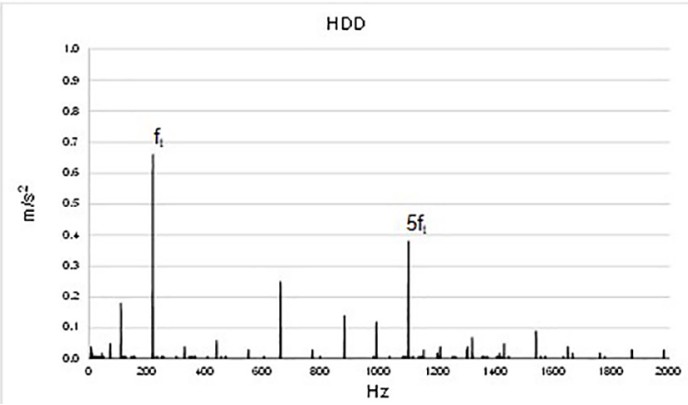

The same effect occurs to VUU and the surface exhibits the same pattern along the feed direction. However, there is less uniformity in the pick feed direction. The surface generated by VDU presents tool marks corresponding to $f_{z}$ along the feed direction. Nevertheless, the distance between the tool marks is not the same along the cross feed direction resulting in variation of the cross-linked pattern. VUD generated a less uniform surface in both directions.

(b)

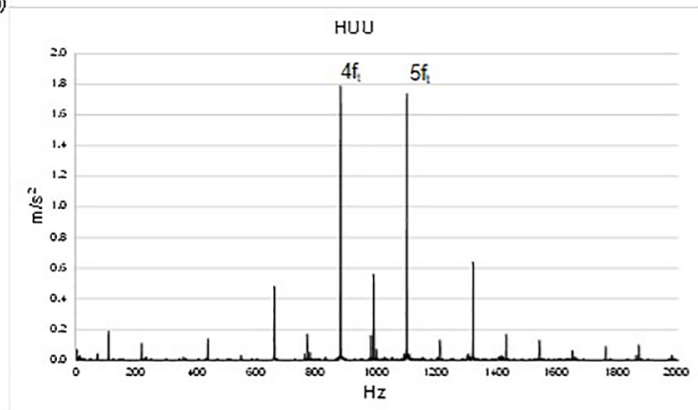

(0)

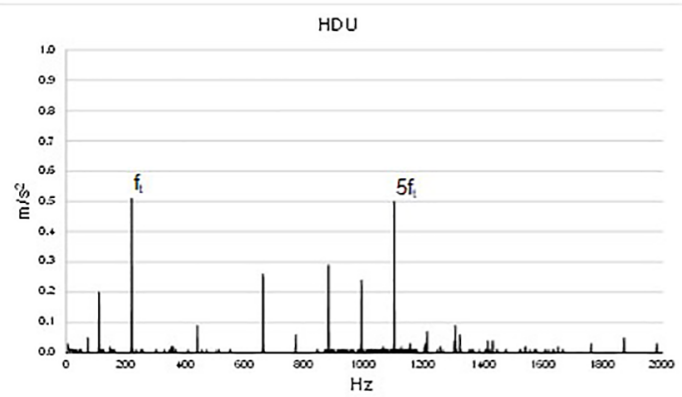

Figure 6. Spectrum of the acceleration signals for horizontal tool path orientations at inclined workpiece angle of $15^{\circ}$ (a) HUD, (b) HUU, (c) HDD, (d) HDU

(a)

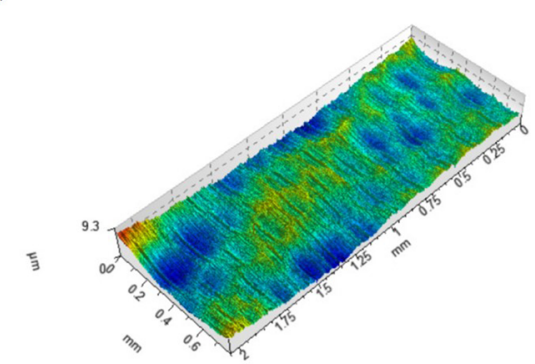

(c)

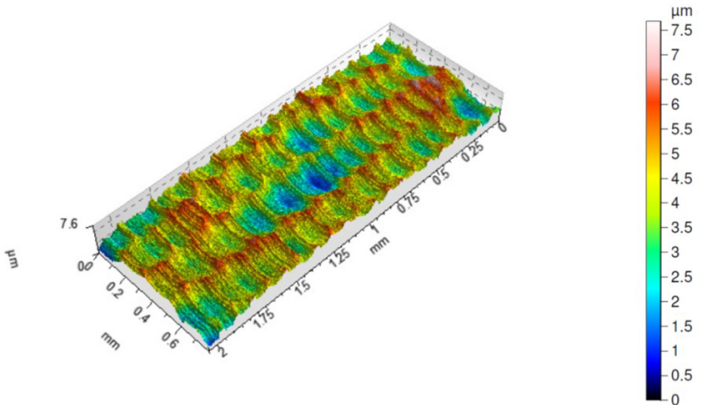

(b)

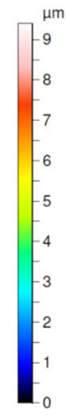

(d)
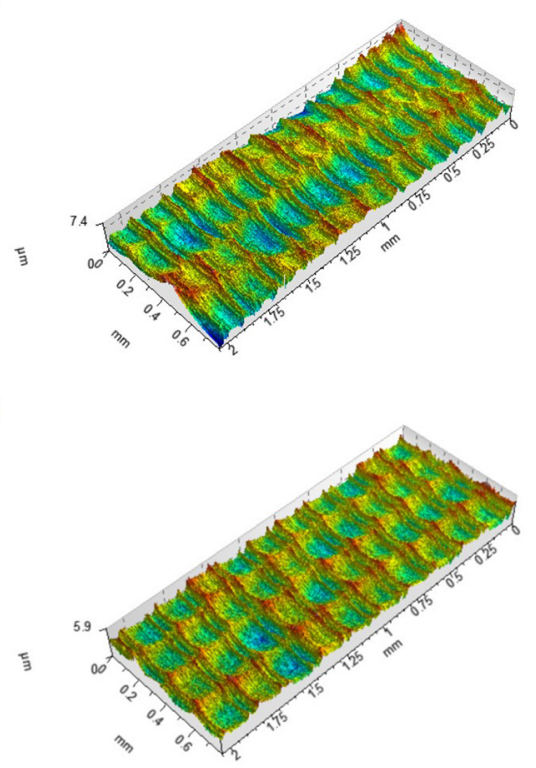

Figure 7. Surface topographies generated by vertical tool path orientations at inclined workpiece angle of $75^{\circ}$ (a) VUD, (b) VUU, (c) VDD, (d) VDU 
Figure 8 depicts that higher magnitudes in the spectrum were found for this condition in comparison to the others. The spectra consist of the harmonics of the spindle speed and the tooth passing frequency. The highest peaks of the spectrum corresponds to the harmonics of the tooth-passing frequency closer to the natural frequency of the system.

Figure 9 displays the surface topographies generated by horizontal tool path orientations at inclined workpiece angle of $75^{\circ}$ topography. HDU and HUD generated a more uniform surfaces in feed and cross feed directions.
HUU and HDU generated a less uniform surfaces with higher vertical distance between the maximum profile peak height and the maximum profile valley depth along the evaluation length.

Figure 10 shows the frequency spectra of the measured acceleration signals for the horizontal tool path orientations at inclined workpiece angle of $75^{\circ}$. The spectra are similar and the highest peaks of the spectrum corresponds to the harmonics of the tooth-passing frequency closer to the natural frequency of the system. Thus, only forced vibrations occurred during the process. (a)

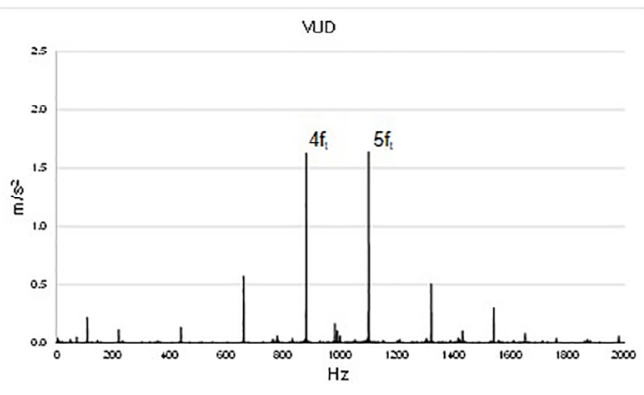

(c)

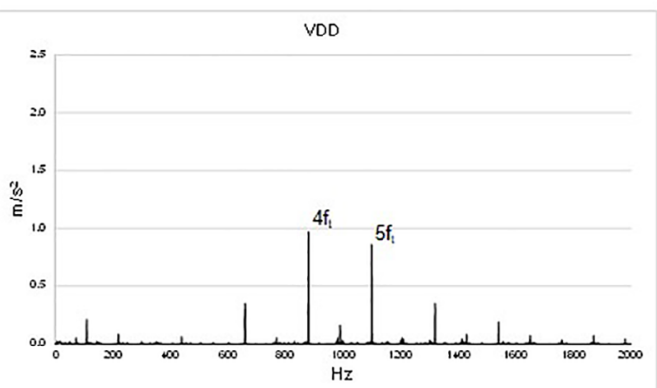

(b)

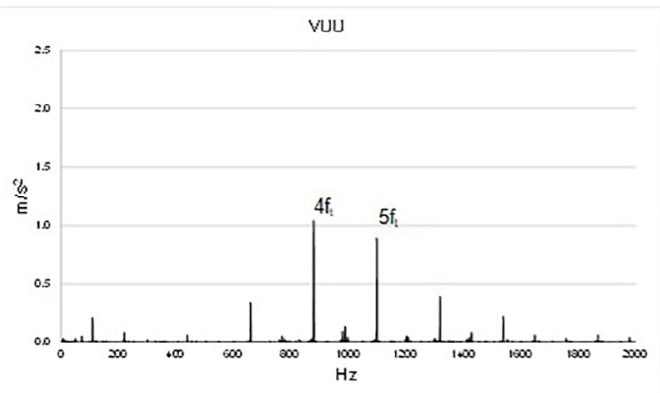

(d)

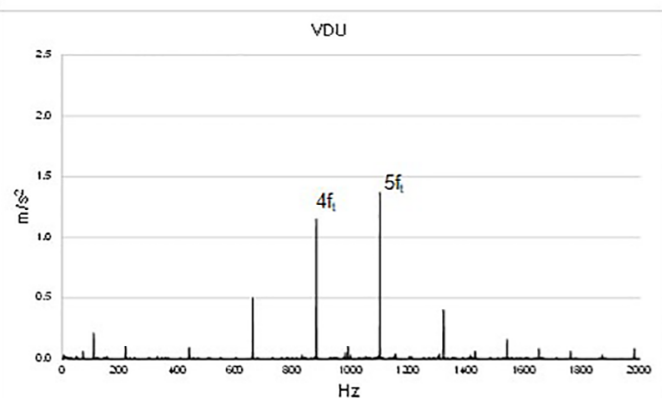

Figure 8. Spectrum of the acceleration signals for vertical tool path orientations at inclined workpiece angle of $75^{\circ}$ (a) VUD, (b) VUU, (c) VDD, (d) VDU

(a)

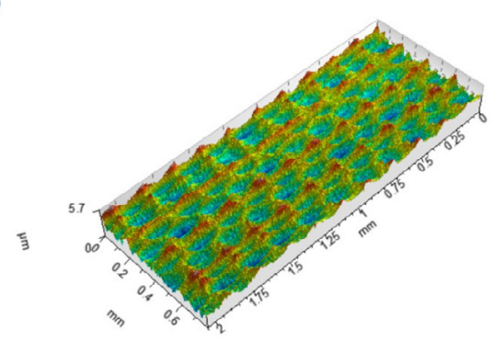

(c)

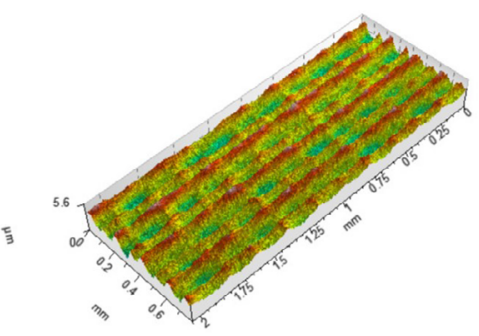

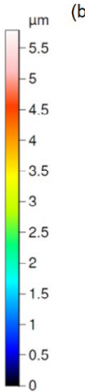

(d)
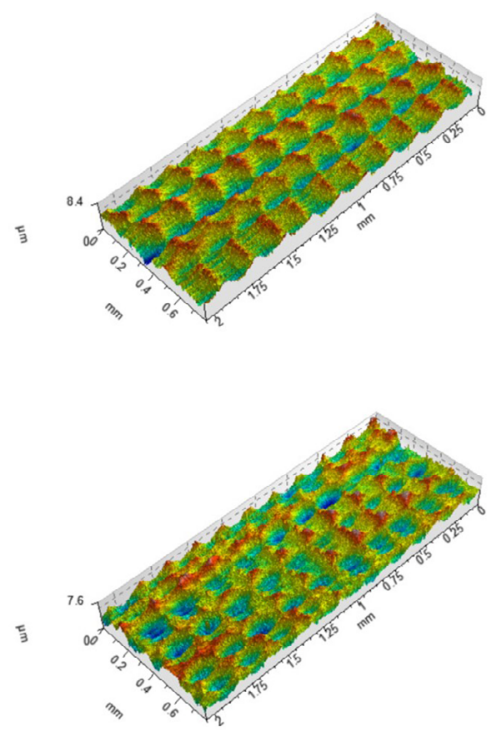

Figure 9. Surface topographies generated by horizontal tool path orientations at inclined workpiece angle of $75^{\circ}$ (a) HUD, (b) HUU, (c) HDD, (d) HDU 
(a)
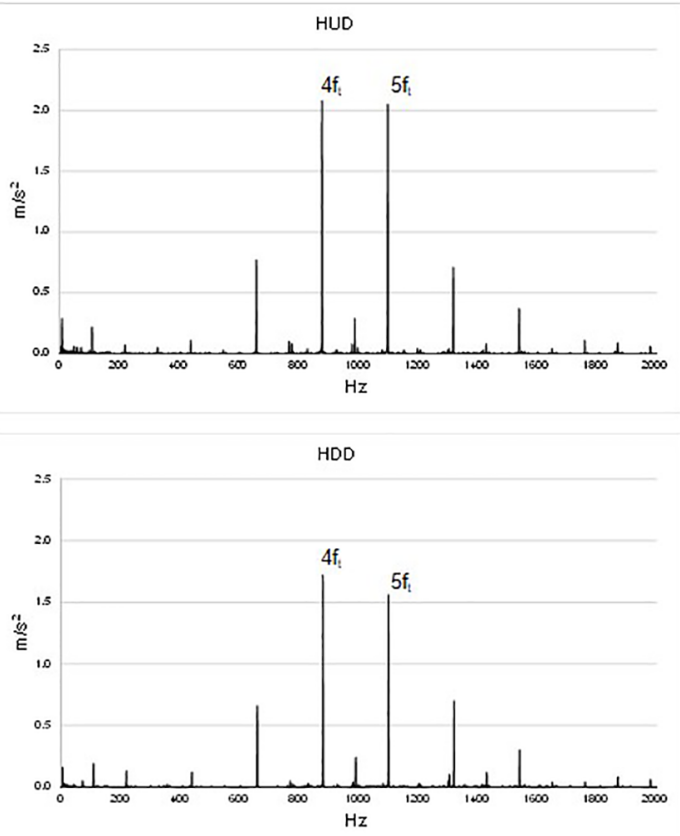

(b)

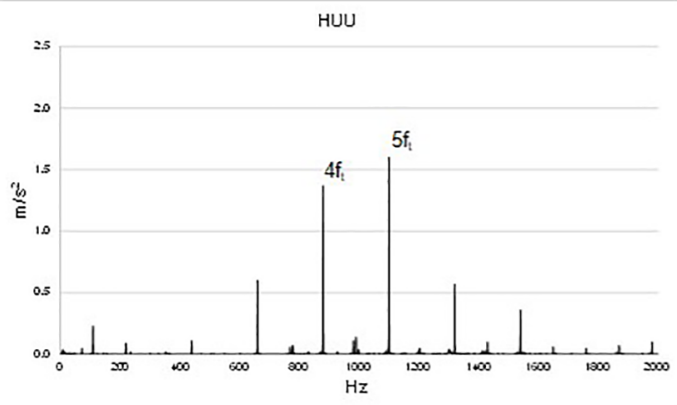

(d)

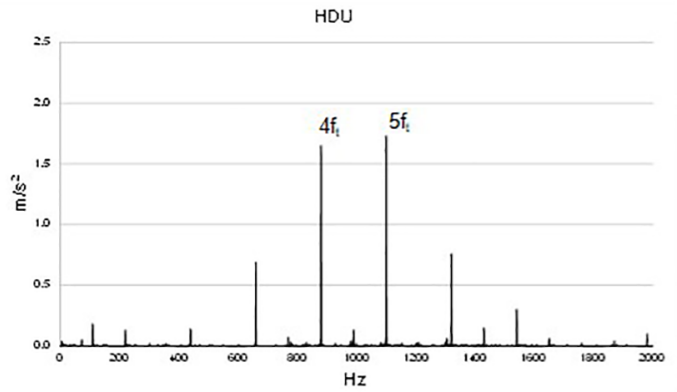

Figure 10. Spectrum of the acceleration signals for horizontal tool path orientations at inclined workpiece angle of $75^{\circ}$ (a) HUD, (b) HUU, (c) HDD, (d) HDU

\section{Conclusions}

The results showed that for workpiece inclination angle of $15^{\circ}$ chatter occurred in vertical upward down-milling and vertical downward up-milling. The spectra presented high peaks at frequencies close to the natural of the system that were not harmonics of the tooth-passing frequency. The machined surfaces were not uniform and the tool marks were not consistent with the cutting parameters. Best surface texture were generated by applying horizontal downward tool paths. The highest peaks in the spectra corresponded to the tooth passing frequency. These conditions produced the least vibration and the tool marks were consistent with pick feed and feed directions.

No chatter marks were observed in the workpieces generated by tool path orientations at inclination angle of $75^{\circ}$. The highest peaks of the spectra corresponded to the harmonics of the tooth-passing frequency closer to the natural frequency of the system. Therefore, only forced vibrations occurred for these conditions. Higher magnitudes in the spectrum were found for vertical upward down-milling that generated a less uniform surface in both directions. The spectra were similar for the horizontal tool path orientations and down-milling produced more uniform surfaces.

\section{References}

1. Nayak M, Sehgal R, Sharma RK. Mechanical Characterization and Machinability Behavior of Annealed AISI D6 Cold Working Steel. Indian Journal of Materials Science. 2015;2015:196178.
2. Parlak N, Ozler L, Dogru N. Investigation of Tool Life in Turning of AISI D6 Steel. Applied Mechanics and Materials. 2013;404:10-15.

3. Altintas Y. Manufacturing Automation: Metal Cutting Mechanics, Machine Tool Vibrations, and CNC Design. Cambridge: Cambridge University Press; 2012.

4. Tlusty J, Ismail F. Basic Non-Linearity in Machining Chatter. CIRP Annals. 1981;30(1):299-304.

5. Altintaş Y, Budak E. Analytical Prediction of Stability Lobes in Milling. CIRP Annals. 1995;44(1):357-362.

6. Altıntaş Y, Lee P. Mechanics and Dynamics of Ball End Milling. Journal of Manufacturing Science and Engineering. 1998;120(4):684-692.

7. Shamoto E, Akazawa K. Analytical prediction of chatter stability in ball end milling with tool inclination. CIRP Annals. 2009;58(1):351-354.

8. Denkena B, Böß V, Nespor D, Gilge P, Hohenstein S, Seume J. Prediction of the 3D Surface Topography after Ball End Milling and its Influence on Aerodynamics. Procedia CIRP. 2015;31:221-227.

9. Subrahmanyam KVR, San WY, Soon HG, Sheng H. Cutting force prediction for ball nose milling of inclined surface. International Journal of Advanced Manufacturing Technology. 2010;48(1-4):23-32.

10. Elbestawi MA, Ismail F, Yuen KM. Surface topography characterization in finish milling. International Journal of Machine Tools and Manufacture. 1994;34(2):245-255.

11. Schulz H, Hock S. High-Speed Milling of Dies and Moulds - Cutting Conditions and Technology. CIRP Annals. 1995;44(1):35-38. 
12. Toh CK. Cutter path orientations when high-speed finish milling inclined hardened steel. International Journal of Advanced Manufacturing Technology. 2006;27(5-6):473-480.

13. Toh CK. Surface topography analysis in high speed finish milling inclined hardened steel. Precision Engineering. 2004;28(4):386-398.

14. Tan L, Yao C, Ren J, Zhang D. Effect of cutter path orientations on cutting forces, tool wear, and surface integrity when ball end milling TC17. International Journal of Advanced Manufacturing Technology. 2017;88(9-12):2589-2602.

15. de Souza AF, Berkenbrock E, Diniz AE, Rodrigues AR. Influences of the tool path strategy on the machining force when milling free form geometries with a ball-end cutting tool. Journal of the Brazilian Society of Mechanical Sciences and Engineering. 2015;37(2):675-687.

16. Scandiffio I, Diniz AE, de Souza AF. Evaluating surface roughness, tool life, and machining force when milling free-form shapes on hardened AISI D6 steel. International Journal of Advanced Manufacturing Technology. 2016;82(9-12):2075-2086.

17. Lim EM, Feng HY, Menq CH, Lin ZH. The prediction of dimensional error for sculptured surface productions using the ball-end milling process. Part 1: Chip geometry analysis and cutting force prediction. International Journal of Machine Tools and Manufacture. 1995;35(8):1149-1169. 